\title{
A vontade em Vygotski: contribuições para a compreensão da "fissura" na dependência de drogas
}

\author{
Júlia Loren dos Santos* \\ Marcelo Dalla Vecchia \\ Universidade Federal de São João del-Rei, Departamento de Psicologia. São João del-Rei, MG, Brasil
}

\begin{abstract}
Resumo: A fissura (craving) é questão central no cuidado a pessoas com problemas decorrentes do uso de álcool e outras drogas, sendo considerada uma incapacidade de controlar o desejo pelo consumo. Contudo, não há definição unívoca desse fenômeno. Investigou-se o conceito de vontade em Lev S. Vygotski (1896-1934), considerando-se que sua abordagem poderia contribuir para a compreensão da fissura. Realizou-se uma revisão da literatura acerca do craving e uma análise focal do conceito de vontade em textos selecionados de Vygotski. Não obstante as controvérsias sobre a definição do fenômeno da fissura, a proposição de Vygotski acerca da vontade como função psicológica superior mediada por motivos auxiliares possibilita ampliar a compreensão do craving. 0 manejo da fissura, assim, depende não somente de uma iniciativa individual, mas também de questionamentos sobre a lógica social, política e histórica que preside os significados sobre o uso de drogas.
\end{abstract}

Palavras-chave: craving (fissura), Vygotski, vontade, drogas.

\section{Introdução}

No âmbito das políticas públicas, as medidas relacionadas ao uso de álcool e outras drogas têm consistido em ações que se concentram, basicamente, nos setores de saúde e segurança. No contexto da segurança, o pronunciamento do presidente Richard Nixon, em 1972, declarando que as "drogas pesadas" eram o principal inimigo dos Estados Unidos, é considerado um marco da doutrina da "guerra às drogas" (Fiore, 2012). Atualmente, pondera-se que o proibicionismo não foi capaz de diminuir a produção e o acesso às drogas tornadas ilícitas, apesar dos vultosos investimentos na eliminação da circulação de substâncias psicoativas ilícitas. A necessidade então colocada de repressão e criminalização gerou um questionável endurecimento da legislação penal relacionada ao tráfico de drogas (Karam, 2008).

Visando legitimar as medidas repressivas, defendia-se que as drogas representavam um problema tanto individual quanto coletivo, sendo seu consumo algo de ordem moral e social (Rodrigues, 2012). Entretanto, preocupações de ordem política e econômica são subjacentes aos supostos interesses de saúde e segurança: "a guerra às drogas se tornou ao mesmo tempo um exercício de controle social e uma estratégia para a ampliação da economia neoliberal a partir do exercício do poder e da violência" (Passos \& Souza, 2011, p. 155). O resultado dessa "guerra" foi um crescimento do mercado global de drogas, bem como a redução dos recursos para a implantação e desenvolvimento de políticas de redução de riscos e danos associados ao uso, em outras palavras,

* Endereço para correspondência: julialoren12@hotmail.com de medidas preventivas (Comissão Global de Políticas sobre Drogas [CBPD], 2011).

As estratégias de redução de danos (RD) visam a uma abordagem integral do ser humano, independentemente do seu padrão de uso, nível socioeconômico etc. Na RD busca-se um resgate dos "aspectos éticos e humanos da relação entre políticas de saúde e consumidores de drogas" (Santos, Soares \& Campos, 2010, p. 996). A RD costuma ser contraposta a uma perspectiva que recorre à abstinência como princípio, meio e fim do tratamento para todo e qualquer usuário de álcool e outras drogas.

Quando se pensa em drogas - principalmente quando se elide que substâncias psicoativas como o álcool, o tabaco, os solventes e os psicofármacos são drogas tornadas lícitas - há uma tendência em associá-las a variados signos do "mal": criminalidade, ilegalidade, vício, descontrole, perversão etc. Contudo, é necessário distanciar-se de um discurso moralista e apreciar os determinantes histórico-sociais e socioculturais do consumo de substâncias psicoativas. Nesse sentido, a atividade consciente humana deve ser historicamente contextualizada mediante a particularidade das circunstâncias nas quais se realiza, compreendendo que ela não pode ser reduzida à mera expressão de um organismo biológica ou psicologicamente considerado (Luria, 1991).

Levando-se em consideração o quadro mais amplo no qual se insere a denominada "economia do tráfico", as substâncias psicoativas ilícitas, tanto quanto as lícitas, são parte das mercadorias produzidas, distribuídas, vendidas e consumidas nos marcos do modo capitalista de produção. No caso das drogas lícitas, a propaganda, a arte e a mídia demarcam o seu lugar enquanto produto 
da indústria cultural e objetos fetichizados de consumo. Como afirmam Tiburi e Dias (2013), "sendo o mercado um referencial moral em uma sociedade calibrada pelo capital, consideramos bom aquilo que pode ser comprado e vendido, desde que se possa ou deseje comprá-lo" (p. 65).

Dessa forma, o debate acerca das políticas sobre drogas transcende aspectos meramente tecnocráticos, havendo diversos elementos que atravessam e tangenciam a relação entre o consumo de drogas, a história, a sociedade e a cultura. No que se refere, especificamente, ao tratamento de pessoas com problemas devidos ao consumo de drogas, o craving, ou "fissura", tem sido destacado como um fenômeno que cria desafios significativos às ações de cuidado. Mesmo que a discussão acerca do craving tenha surgido em estratégias de tratamento que priorizam a abstinência como método, o manejo da fissura também é importante em ações subsidiadas pela posição ético-política da RD. Assim, é preciso considerar que a produção de conhecimento acerca da "fissura" será permeada por fundamentos científico-filosóficos que precisam ser devidamente debatidos, exigindo uma postura analítica e interpretativa diante do fenômeno.

Craving ou "fissura" refere-se, na maioria das vezes, a um estado corporal e mental de desejo intenso pelo uso de determinada substância psicoativa, manifestado por certo indivíduo, e direcionado a uma droga previamente consumida. Essa descrição é a mais utilizada. Os próprios usuários habitualmente atribuem à fissura a incapacidade de controlar seu desejo pelo consumo, o que os levaria a cometer roubos, furtos ou estelionato. O craving é considerado um importante fator de manutenção do uso prejudicial de álcool e drogas, bem como de retorno ao consumo em períodos de abstinência ou não.

Os estudos acerca do craving demonstram variadas compreensões do seu significado e manifestação, recorrendo-se a diferentes modelos teórico-metodológicos para a investigação e abordagem, reforçando a importância de debatê-los (Araújo, Oliveira, Nunes, Piccoloto, \& Melo, 2004a). Os estudos conceituais e metodológicos evidenciam a necessidade de ampliar e diversificar as investigações em torno desse fenômeno visando a elaboração de novas estratégias de avaliação e intervenção. Como afirmam Araújo, Oliveira, Pedroso, Miguel e Castro (2008),

não existe uma única forma de mensurar o craving que sirva para todas as situações, entretanto são necessárias novas pesquisas para que as medidas de avaliação do craving possam oferecer subsídios para a melhor definição deste construto, bem como dos fatores a este relacionados. (p. 61)

Dado esse panorama, que envolve aspectos históricos, econômicos, sociais, epistemológicos e técnicos relacionados ao consumo de drogas e o craving, surgem alguns questionamentos: é possível compreender a "fissura" de forma mais abrangente, sem recair em extremos ou reducionismos de tipo biológico ou ambiental? Em que medida essa discussão nos auxilia a compreender a origem e o desenvolvimento do craving?

O conceito de vontade como uma função psicológica superior foi abordado pelo psicólogo bielo-russo Lev Semenovich Vygotski (1896-1934), reconhecido como o fundador da teoria histórico-cultural do desenvolvimento das funções psicológicas superiores. Interessante notar que, no senso comum, o controle da vontade de consumir, ou, em outras palavras, a necessidade de ter "força de vontade" contra o impulso para o uso, são considerados elementos centrais para o engajamento (ou não) no tratamento de problemas decorrentes do uso de álcool e outras drogas.

Vários estudos destacam a importância de investigar o craving, delineando seu conceito, implicações, origens etc., para que novos tratamentos e instrumentos de intervenção sejam elaborados, uma vez que a "fissura" é elemento importante no consumo problemático de álcool e drogas (Araújo et al, 2008; Vela, Abadías, Vidal, Munuera, \& Carvacho, 2004). Dado que há necessidade de se compreender eventos de caráter psicológico atinentes à relação entre o consumo de drogas e o craving, entende-se que uma sistematização do conceito de vontade em Vygotski pode se apresentar como via promissora para uma compreensão mais abrangente do fenômeno.

\section{Metodologia}

A pesquisa bibliográfica foi adotada como desenho metodológico geral neste estudo conceitual. Para Lima e Mioto (2007), esse método "implica em um conjunto ordenado de procedimentos de busca por soluções, atento ao objeto de estudo, e que, por isso, não pode ser aleatório" (p. 38). Assim, foram coletadas e analisadas criticamente as informações disponíveis acerca do tema em bases de dados bibliográficas. É de suma importância que seja preservado, no desenvolvimento da pesquisa, o rigor metodológico; no entanto, como afirma Prestes (2012), "é preciso não ter medo de ousar e de inovar. O rigor metodológico em qualquer pesquisa é também uma criação" (p. 407).

Foram colocadas, então, determinadas questões orientadoras: é possível que uma sistematização do conceito de vontade contribua com a compreensão do craving enquanto fenômeno do processo de tratamento? $\mathrm{O}$ estudo do conceito de vontade, com base na teoria histórico-cultural do desenvolvimento das funções psicológicas superiores de Vygotski, pode auxiliar no desenvolvimento dos métodos e técnicas de tratamento, em especial para profissionais e pessoas que buscam manejar a "fissura" ou craving?

Em uma primeira etapa do ciclo de pesquisa, foram aprofundas as definições de craving/“fissura”, buscando precisar as lacunas existentes na literatura científica. 
Para o levantamento das informações analisadas recorreram-se às seguintes bases de dados de indexação de periódicos científicos: Scientific Electronic Library Online (SciELO), Literatura Latino-Americana e do Caribe em Ciências da Saúde (LILACS) e Periódicos Eletrônicos de Psicologia (PePSIC). As buscas foram feitas recorrendo-se aos termos: craving, "fissura", "vontade", e "dependência de álcool e outras drogas".

Na segunda etapa, a análise focal do conceito de vontade proposto por L. S. Vygotski ocorreu por meio da sondagem de determinados textos do autor disponíveis em suas Obras escogidas (Vygotski, 1995a, 1995b, 1995c, 1999, 2001a, 2001b, 2003, 2006a, 2006b). A seleção teve por base o estudo de Selau e Boéssio (2012) sobre o conceito de vontade nas obras de Vygotski. Quando possível, recorreu-se aos textos disponíveis em língua portuguesa, identificados em duas compilações editadas pela Martins Fontes: Construção do pensamento e da linguagem (2001) e O desenvolvimento psicológico na infância (2003).

A seguir, na terceira etapa, como procedimento de categorização dos resultados, foram confeccionados fichamentos para: a) análise de informações relativas às definições existentes de craving; e b) revisão do desenvolvimento e aplicabilidade do conceito de vontade nas obras citadas de Vygotski, criando-se esquemas teóricos que facilitassem a sistematização dos conceitos. Finalmente, realizou-se a análise de dados, buscando-se verificar a hipótese de compreensão do craving tendo como base o conceito de vontade, identificando e descrevendo em que medida é possível concebê-lo como uma alteração dessa função psicológica superior com base na literatura abordada.

\section{0 que é o craving?}

Em face das controvérsias acerca do conceito de craving decorrentes das diferentes compreensões do fenômeno devido aos distintos modelos explicativos, em 1954 dois comitês de especialistas se reuniram visando delimitar o significado do termo no contexto científico: o Expert Committee on Alcohol e o Expert Committee on Mental Health of the World Health Organization. Naquele momento, o craving foi definido como uma ânsia urgente ou incontrolável (urge) pelo consumo de drogas, que poderia ser dividido em: a) desejo físico, como no caso dos sintomas de abstinência do álcool; e b) desejo simbólico, enquanto gatilho tanto para o início do uso excessivo quanto para a recaída (Kozlowski, \& Wilkinson, 1987).

Uma das conceituações mais influentes nas formulações teóricas acerca do tema é a de Alan Marlatt. Esse autor propôs uma definição fenomenológica e, em seus primeiros estudos, conceituou o craving como um forte desejo para o alívio de sintomas desagradáveis que compõem um quadro de abstinência (Kozlowski, \& Wilkinson, 1987). Entretanto, ao passo que avançaram as investigações, Marlatt também identificou no craving um estado subjetivo mediado pela expectativa de resultados positivos associados ao uso de determinada droga (Marlatt, 1987).

A partir desses primeiros estudos constituiu-se a definição técnica do termo, visando abarcar a necessária contextualização para que o fenômeno pudesse ser melhor compreendido. Kozlowski e Wilkinson (1987) propuseram que perguntas claras e diretas fossem feitas aos usuários de drogas acerca da sua experiência com o craving, considerando a necessidade de articular na definição o desejo pelo uso e a decisão de usar.

Araújo et al (2004a) retomam o que foi afirmado por Alan Marlatt a respeito da distinção entre craving e compulsão. O craving seria um desejo subjetivo em relação aos efeitos de determinada droga, enquanto a compulsão seria a intenção comportamental de consumir a substância (Marlatt, 1987). Assim, o craving, estando associado ao desejo, abrange a dimensão do "eu quero", enquanto a compulsão ocuparia a dimensão do "eu vou", direcionando o comportamento para o ato do consumo.

Nota-se que a distinção entre desejo e intenção de consumo possibilita discriminar duas manifestações distintas do craving. Araújo et al. (2008), em sua revisão, buscando uma abordagem mais abrangente e multidimensional, elencam quatro elementos no fenômeno do craving: 1) o desejo pela substância; 2) a antecipação de resultados positivos do consumo; 3) o alívio dos sintomas de privação; e 4) a intenção de realizar o uso.

Atualmente, esse fenômeno é descrito pela maioria dos pesquisadores como um desejo intenso de usar determinada substância. Sua manifestação pode ocorrer em três momentos: durante o uso, ao longo da fase de desintoxicação e depois de prolongados períodos de interrupção do consumo da substância (Araújo et al., 2004a). Sabe-se também que a "sensação de craving possui componentes fisiológicos, cognitivos, afetivos e comportamentais" (Santos, Rocha, \& Araújo, 2014, p. 122) e que, por isso, sua análise e as suas estratégias de manejo devem intervir em um amplo conjunto de fatores. Visto ser o craving uma experiência individual, é necessário desenvolver um planejamento personalizado para o tratamento de cada sujeito (Santos et al., 2014).

\section{Principais modelos explicativos do Craving}

Para o modelo neurobiológico, o craving pode ser provocado por gatilhos tais como imagens, sons, odores e contextos ambientais. Esses gatilhos seriam sugestões cognitivas internas ou externas que estão, de alguma forma, relacionadas ao uso de drogas. O estabelecimento dessa relação ocorre por meio do pareamento entre o uso repetido da droga e variáveis internas ou ambientais, armazenadas em conjunto na memória. 
Em decorrência do pareamento, os circuitos neurais de uma pessoa se tornam hipersensíveis aos estímulos relacionados à droga, desencadeando um forte desejo de consumo ao contato. Consequentemente, a principal estratégia para o manejo do craving, nesse modelo, consiste em reconhecer os gatilhos que desencadeiam esse forte desejo, para evitar situações em que estejam presentes (Zeni \& Araujo, 2011).

Para o modelo cognitivo, por sua vez, situações externas/ambientais e internas estão envolvidas no processo de recaída de uma pessoa que busca interromper o uso de determinada droga. As alterações de humor, por exemplo, ativarão crenças centrais que o indivíduo possui e crenças aditivas em relação ao uso da substância. Essas crenças desencadearão pensamentos automáticos que farão advir o craving (Santos et al., 2014). Também está presente, nesse modelo, a compreensão de que as situações que estimulam o uso da droga envolvem a relação entre crenças aditivas e crenças de controle:

Os sintomas fisiológicos de craving, geralmente vivenciados como forte ansiedade, "acionam" então crenças aditivas permissivas (como "usarei apenas um pouco") que podem levar ao uso da substância. Juntamente com essas crenças aditivas, que estão associadas à busca do prazer (ou alívio do desprazer) e sensações de bem-estar, o paciente pode apresentar também crenças de controle (como: "terei prejuízos com o uso"), que podem, assim, diminuir a necessidade de consumir a substância psicoativa (Santos et al., 2014, p. 122).

As técnicas de manejo do craving propostas por esse modelo envolvem estratégias de enfrentamento que buscam fortalecer as crenças de controle. Dentre as principais técnicas, destaca-se a substituição por imagem positiva (SIP), que é a visualização dos benefícios advindos da interrupção do uso de determinada substância, buscando fortalecer a autoeficácia durante a abstinência (Santos et al, 2014).

O modelo comportamental preconiza a diferenciação entre o craving e a compulsão, sendo o primeiro o desejo motivacional e o segundo a intenção comportamental. Entretanto, no processo de condicionamento que compreende a manifestação do craving, esses dois fenômenos estão articulados. Desse modo, um estímulo externo (conditioned stimulus - CS) - por exemplo, a visão de um maço de cigarros - desencadeia uma resposta de craving (conditioned response - $\mathrm{CR}$ ) que, em seguida, origina um comportamento compulsivo, que pode ou não ser seguido por uma resposta de uso da substância e seus consequentes estímulos reforçadores (Marlatt, 1987). As estratégias de manejo adotadas segundo esse modelo consistem, então, em promover novos condicionamentos em relação ao uso da droga, principalmente o controle das variáveis ambientais, para que o condicionamento que desencadeia o craving entre em extinção.

\section{Estratégias, instrumentos e modalidades de avaliação do craving}

A avaliação do craving, nas pesquisas ou nas práticas profissionais, segue abordagens principalmente quantitativas. Contudo, a inexistência de um consenso sobre a conceituação do fenômeno gera diferentes compreensões entre o que está sendo avaliado e o que precisa de avaliação enquanto elementos da "fissura". Além disso, em tese, determinados aspectos poderiam caracterizar melhor o craving do que outros, dificultando sua investigação, por existirem manifestações distintas de pessoa para pessoa (Corrêa Filho \& Baltieri, 2012).

Em relação às abordagens quantitativas, os principais instrumentos de medida utilizados para a avaliação do craving são: a) Escala para avaliação do craving, constituído por 11 questões que avaliam a manifestação do craving nos primeiros três dias de internação; b) Questionnaire of Smoking Urges e Questionnaire of Smoking Urges - Brief, sendo o primeiro composto por 32 questões e o segundo por 10, ambos avaliando o craving por tabaco; c) Escala Analógico-Visual para o Craving, consistindo em uma reta que varia de zero a 10 na qual o usuário escolhe uma nota que melhor defina o nível de fissura; d) Cocaine Craving Questionnaire - Brief e Cocaine Craving Questionnaire - Brief - Versão Brasileira Adaptada para o Crack, sendo que a primeira avalia o craving por cocaína e a segunda por crack, e ambas consistem em uma escala do tipo Likert que varia de um a sete, composta por dez questões; e) Obsessive Compulsive Drinking Scale (OCDS), escala do tipo Likert composta por 14 questões, variando as respostas de zero a quatro; e f) Marijuana Craving Questionnaire - MCQ-SF/Versão Brasil, contendo 12 itens com as respostas dadas a partir de uma escala do tipo Likert que varia de 1 a 7 (Araújo et al., 2007; Araújo, Pedroso, \& Castro, 2010; Araújo et al, 2011; Balbinot et al., 2011; Balbinot, Araujo, \& Santos, 2014; Corrêa Filho \& Baltieri, 2012; Pedroso, Castro, \& Araujo, 2009; Santos, Rocha, \& Araújo, 2014).

No que diz respeito às análises qualitativas, Chaves, Sanchez, Ribeiro e Nappo (2011) apresentam um método de investigação do craving no qual, para avaliar a fissura, os pesquisadores realizaram uma entrevista com usuários de crack buscando investigar valores, crenças e representações associadas ao consumo. Os tópicos que constituíram o roteiro da entrevista procuravam averiguar o "perfil sociodemográfico, histórico do uso de crack, efeitos do crack, vivência da fissura e suas consequências, comportamento de risco associado à fissura, padrão compulsivo de consumo de crack (binge) e agressividade relacionada à fissura por crack" (Chaves et al., 2011, p. 1.170). O estudo das principais crenças, valores e representações observadas por estes autores apontou que o craving é o principal fator para manutenção do uso, levando os usuários a se submeterem a situações 
que outrora não admitiriam para si, como a prostituição, a manipulação de pessoas, a criação de dívidas e o envolvimento em furtos e assaltos.

\section{Outros achados relevantes de pesquisas acerca do craving}

As investigações relacionadas ao craving destacam, principalmente, os fatores associados ao fenômeno. Independentemente do modelo explicativo de base, evidencia-se a importância de identificar as situações internas (motivos) e externas (necessidades) que o desencadeiam. Zeni e Araújo (2011) identificaram que consumir álcool, sentir emoções intensas, ter dinheiro na mão, ver usuários de crack e sentir-se sozinho são gatilhos para a expressão do craving por crack. Araújo et al. (2007) identificaram correlações positivas, porém baixas, do craving por tabaco com sintomas de depressão, ansiedade e com a quantidade de cigarros fumados por dia, mas não foi localizada essa correlação em relação à idade, escolaridade, idade em que começou a fumar e motivação para parar de fumar. Os sonhos com álcool também demostraram uma associação positiva com o craving pela substância (Araújo, Oliveira, Piccoloto, \& Szupszynski, 2004b). Balbinot et al, (2014), por sua vez, demonstraram associação entre alteração da frequência cardíaca e craving, o que autorizaria a análise do craving a partir de um parâmetro fisiológico.

As estratégias de manejo ou controle do craving também são amplamente abordadas nas pesquisas. Podem ser desde estratégias terapêuticas, como a utilização da técnica cognitiva de substituição por imagem positiva, até técnicas desenvolvidas pelos próprios usuários, como comer, encontrar satisfação em atividades rotineiras e usar benzodiazepínicos (Santos et al., 2014; Chaves et al., 2011). Chaves et al. (2011) destacam que as técnicas de controle são singulares, mas que "quanto maior a satisfação do sujeito com a sua própria vida, menor a possibilidade de sucumbir à fissura" (p. 1.173).

Pedroso et al. (2009) destacam que novas pesquisas precisam evidenciar as particularidades do uso de cada substância psicoativa e a manifestação do craving, uma vez que "o desejo só pode ser entendido em sua relação com o objeto desejado e com as consequências dessa realização" (p. 219). Além disso, destaca-se a necessidade de diferenciação dos fenômenos do craving e da compulsão, para que se compreendam as particularidades inerentes ao desejo pelo uso de drogas.

No que tange ao tratamento medicamentoso, Corrêa Filho e Baltieri (2012) pontuam que atualmente existem quatro medicamentos aprovados pela Food and Drug Administration para o tratamento do alcoolismo, sendo que acamprosato e naltrexona oral e injetável demonstraram alguma capacidade de amenizar os sintomas de craving, contribuindo com o tempo de abstinência. Todavia, os autores afirmam que esses resultados não são conclusivos.
Enquanto algumas pesquisas defendem o uso da internação como estratégia de controle do craving, outras sugerem que dela se prescinda. Araújo et al. (2004a), Araújo et al. (2004b), Balbinot et al. (2011) e Chaves et al. (2011) compreendem que a internação deve ser considerada porque impediria o contato do usuário com o contexto e com as pessoas junto das quais o uso ocorre. A pesquisa de Araújo et al. (2007), nesse sentido, é digna de atenção. Os autores analisaram o craving por tabaco a partir do tempo de abstinência, com três intervalos de avaliação no modelo experimental: zero minuto, 30 minutos e 60 minutos. Os autores observaram que o aumento do craving por tabaco era diretamente proporcional ao tempo de abstinência. Não obstante, Kozlowski e Wilkinson (1987) destacaram a observação de Glassman, Jackson, Walsh, Roos e Rosenfeld (1984), para os quais o sintoma mais imediato, consistente e severo da suspensão do uso do tabaco, é o craving. Esses dados podem constituir um indicador de alerta para a retirada brusca da droga, como costuma ocorrer nas abordagens de abstinência que têm a internação como corolário.

Santos, Rocha e Araújo (2014), em pesquisa realizada em um contexto de internação, notaram que durante exposição a materiais relacionados ao crack:

alguns pacientes relataram que sentiram o craving de maneira atenuada, pois se encontravam em ambiente protegido, continente e afastado do acesso. Em outros pacientes, pelo contrário, pode-se identificar intensa fissura, percebidos também por sintomas físicos como tremores, sudorese e inquietação (p. 125).

Dessa forma, nota-se que a promoção do bem-estar do usuário é a estratégia de manejo com melhores resultados, sendo que esse aspecto perpassa a compreensão do craving em diferentes modelos explicativos do fenômeno.

\section{A compreensão da vontade na obra de L. S. Vygotski}

Vygotski (1925/1999) afirma que qualquer movimento/gesto é realizado pela pessoa, inicialmente, de maneira inconsciente; a vontade gera um movimento, um ato, ações, palavras; depois, uma reação secundária, ou seja, o significado dado ao movimento produzido se converte na base de sua consciência. Nesse sentido, a experiência histórica e social antecede a consciência. É importante sinalizar que ao falar da realização inconsciente de um movimento/gesto a partir das bases históricas e sociais do ser humano, Vygotski não faz referência a uma possível "linguagem cifrada" dos processos psicológicos conforme propõe a psicanálise. A proposição de um movimento inconsciente se traduz em Vygotski como uma ação que ainda não foi significada 
no contexto histórico, cultural e relacional do indivíduo, mas que se realiza em correspondência à universalidade humana (Santos \& Leão, 2014).

Vygotski (1931/1995) também aponta em pesquisas experimentais conduzidas junto de seus colaboradores que o que caracteriza o domínio da conduta é a possibilidade de eleger algo entre várias opções. Demonstra que as escolhas são direcionadas por motivos auxiliares, que consistem no resultado das diferentes experiências vividas por uma determinada pessoa. É importante ressaltar que os motivos auxiliares não controlam as decisões, mas as influenciam. Ampliando a análise do conceito, Vygotski demonstra que a vontade é desenvolvida, sendo, portanto, um produto da cultura em que o ser humano está inserido (Selau \& Boéssio, 2012).

Após empreender ampla revisão das investigações psicológicas acerca do desenvolvimento humano até meados da década de 1920, Vygotski e seus colaboradores notam uma dificuldade a ser superada a respeito do método de investigação na psicologia. Para ele, a maioria das teorias psicológicas centra-se na investigação da relação entre estímulo e resposta, sem considerar os fatores históricos que constituem a relação entre esses dois fenômenos. Devido a isso, propõe a metodologia histórica como uma nova forma de investigação dos fenômenos psicológicos (Vygotski, 1931/1995a).

O estudo histórico dos processos de desenvolvimento humano deve examinar os fenômenos em movimento, considerando, assim, a constituição dialética dos elementos presentes, implicando em um processo de sucessiva incorporação por superação (aufhebung) no qual é preciso apreender fases e mudanças desde o advento à decadência. Para justificar a pertinência desse novo caminho de pesquisa, Vygotski propõe que, assim como há nos animais e nas plantas órgãos rudimentares, que atualmente estão inativos, mas que são fundamentais para o conhecimento do desenvolvimento desses seres, ocorre também dessa forma com as funções psicológicas do ser humano. Por isso, compreender o permanente movimento de criação, estabilidade e transformação do psiquismo consiste em perceber que a historicidade do ser humano reflete uma construção psicológica que se modifica, mas também conserva, ou seja, é realizada pela via do negativo que incorpora no novo elementos do contrário. Nesse sentido, seria pertinente definir, com base na psicologia histórico-cultural, os conceitos de funções psicológicas inferiores e superiores (Vygotski, 1995a).

As funções psicológicas inferiores (ou elementares) compreendem aquelas de caráter rudimentar, determinadas, sobretudo, pelas características biológicas da psique. Essas funções são, ao longo do tempo, superadas por meio do desenvolvimento das funções psicológicas superiores, como o pensamento conceitual, a atenção voluntária, a memória lógica e a vontade direcionada a um fim. As funções psicológicas superiores são produtos do desenvolvimento cultural e apresentam como traço peculiar o fato de que, diferentemente das funções inferiores, não são formadas pela simples relação entre um estímulo e uma resposta, pois nessa relação há estímulos intermediários (Vygotski, 1931/1995b). Assim, a superação presente nas funções psicológicas superiores tem como destaque a função mediadora dos estímulos-meios:

Lo nuevo consiste en que es el propio hombre quien crea los estímulos que determinan sus reacciones y utiliza esos estímulos como medios para dominar los procesos de su propia conducta. Es el propio hombre el que determina su comportamiento con ayuda de estímulos medios artificialmente creados (Vygotski, 1931/1995a, p. 77).

As funções psicológicas superiores, assim, têm a especificidade de serem constituídas historicamente pelo próprio ser humano, que introduz estímulos artificiais na busca de conferir significação e controle ao seu comportamento. Esse propósito será realizado por meio dos signos, que atuam de fora do organismo. Dessa forma, todas as funções psicológicas têm como base processos de mediação (ou seja, não são respostas imediatas) que incorporam o "emprego de signos como meio fundamental de orientação e domínio nos processos psíquicos" (Vygotski, 1932/2001a, p. 161). Os signos são, portanto, estímulos mediadores para que o homem possa influenciar a si mesmo, dominando a sua atividade psicológica, mas, também, influenciar ao outro, proporcionando uma nova orientação ou reestruturação das funções psicológicas (Vygotski, 1931/1995a, 1931/1995b).

O estudo do papel dos signos no desenvolvimento humano relaciona-se à própria estruturação da consciência, pois evidencia que o corpo pode se constituir como excitante do homem, por meio de seus próprios atos e em face dos atos de outrem: "é consciente o que se transmite a outros sistemas na qualidade de excitante e provoca neles uma resposta. A consciência é sempre um eco, um aparelho de respostas" (Vygotski, 1925/1999, p. 71-72). Essa compreensão de consciência abarca a primeira concepção de Vygotski sobre esse fenômeno. Para Toassa (2006), há outras duas acepções na obra do autor: a consciência como um atributo e enquanto sistema psicológico existente entre o homem e o meio, sendo que, nesta última acepção, que supera as demais por incorporação, o uso da palavra demarca o caráter distinto do signo dentre os demais estímulos. Por meio dessa análise, admite-se, considerando os avanços na obra de Vygotski (1932/2001b), que o "pensamento e a linguagem são a chave para a compreensão da natureza da consciência humana" (p. 485), de modo que "na consciência a palavra é precisamente aquilo que, segundo expressão de Feuerbach, é absolutamente impossível para um homem e possível para dois. Ela é a expressão mais direta da natureza histórica da consciência humana" (p. 486). 
Segundo Vygotski, a compreensão da vontade como uma função psicológica superior é fundamental para descrever a essência da consciência, por operar em inter-relação sistêmica com as demais funções psicológicas na sua constituição. Isso ocorre porque $\mathrm{o}$ ato volitivo é formado a partir de uma experiência história que possibilita uma experiência social, fornecendo ao homem a ilusão de que pensa em fazer algo e por isso o faz, caracterizando, assim, o aspecto consciente da expressão da vontade que produz uma ação (Vygotski, 1925/1999). Por ser uma função psicológica superior, a vontade também só poderá ser completamente desvelada pelo método científico histórico, pois sua expressão refletirá a superação de aspectos rudimentares do psiquismo humano. Sendo assim, para compreender a vontade, faz-se necessário compreender os determinantes socioculturais da expressão integral do comportamento humano, inclusive em relação às manifestações da consciência, e identificar as formas de atuação dos signos enquanto meios auxiliares da atividade humana (Vygotski, 1995a).

O estudo da vontade é permeado por compreensões espiritualistas, admitindo, por exemplo, a ideia de que há forças não identificáveis que atuam fora do corpo e que levam o ser humano ora a dominar a sua natureza, como quando se resiste à dor voluntariamente, e ora a ceder aos seus instintos. Willian James, por exemplo, afirmava que a possibilidade de resistir à dor decorre da "presença do fluxo de uma certa energia espiritual que, ao se unir ao impulso mais fraco, é capaz de garantir a vitória sobre um fator mais forte" (Vygotski, 1932/2003, p. 138). Todavia, o diferencial da proposição vygotskiana consiste em admitir a possibilidade de investigar os meios pelos quais é possível realizar o domínio do próprio comportamento (Vygotski, 1995b). Nesse sentido, compreende-se a vontade como um fenômeno concreto da existência humana e, portanto, sujeita à investigação científica.

As funções superiores introduzem como categoria superada (aufhebung) as funções inferiores. Partindo desse pressuposto, Vygotski se propôs a estudar patologias que provocam alterações psicológicas, com a hipótese de que essas doenças gerariam alterações do desenvolvimento ontogenético que precisam ser aquilatadas. Para justificar essa hipótese e explicar o caráter de superação presente nas funções psicológicas superiores, Vygotski compara histeria, afasia e esquizofrenia, visando determinar o caráter essencialmente novo presente nas funções psicológicas superiores, considerando em especial a atenção, a memória, a percepção, o pensamento e a vontade. Para ele, nestas três condições as alterações no desenvolvimento do pensamento são centrais (Vygotski, 1931/2006a).

Vygotski considera que, na histeria, a psique está muito propensa às descargas impulsivas afetivas. Isso significa que nesta condição a vontade direcionada a um fim transmuta a posição de controle com a hipobulia, uma espécie de função psicológica inferior da vontade que está mais sujeita aos mecanismos impulsivos das emoções. Por ser uma função psicológica superior, a vontade supera incorporando o estado anterior (inferior), classificado por Vygotski como hipobúlico. Nesse sentido, a doença se manifesta devido a algum evento que provocou a desintegração da vontade enquanto função psicológica superior, fazendo com que as instâncias inferiores, conservadas no processo de superação, assumam, novamente, sua máxima expressão de acordo com as leis primitivas que as governam (Vygotski, 1931/2006a).

Nessas circunstâncias, a vontade não é direcionada para um fim, e sua expressão em histéricos é regredida: "no es que los histéricos tengan poca fuerza de voluntad, lo que no tienen es um propósito firme. La debilidade del objetivo es, justamente, la esencia psíquica del estado que padece um gran numero de histéricos crónicos" (Vygotski, 2006a, p.171). A ausência desse "propósito firme" enunciado por Vygotski corrobora algumas das peculiaridades por ele identificadas e atribuídas à vontade, como governar a si mesmo e ao próprio comportamento, estabelecer objetivos e orientar as suas ações a partir das consequências por ela produzidas (Vygotski, 1931/2006a).

Segundo Fonseca-Janes e Lima (2013), na obra de Vygotski distinguem-se momentos do desenvolvimento da função psicológica do pensamento: a) pensamento sincrético, em que há uma manifestação agregada e desorganizada dos conteúdos cognocíveis; b) pensamento por complexo, caracterizado pelo agrupamento dos objetos partindo das representações que se tem sobre eles e não de suas características estáveis; e c) pensamento conceitual, no qual é expresso "un profundo y amplio reflejo del objeto de la realidad en toda su diversa complejidad, sus nexos y relaciones con el resto de la realidad" (Vygotski, 1931/2006b, p. 80). Nesse sentido, Vygotski afirma que o pensamento tem um papel central no desenvolvimento de todas as funções psicológicas superiores, ou seja, do processo integral da consciência, sendo que a partir do pensamento em conceitos se torna possível estruturar a vontade dirigida a um fim. Assim, nos casos de histeria há também uma perturbação da atividade intelectual que orienta o comportamento (Vygotski, 1931/2006a).

Considerando-se especificamente as contribuições de seus estudos sobre a histeria, pode-se perceber que o processo de desenvolvimento da vontade ocorreria, segundo Vygotski, com base nas seguintes etapas: 1) expressão máxima dos estados impulsivos e afetivos, 2) superação da hipobulia enquanto instância independente; e 3) aparecimento da vontade orientada para um fim. Compreendendo esse processo e identificando a regressão que ocorre nos casos de histeria, torna-se possível pensar como esse retorno a um estado inferior também é expresso em outras patologias (Vygotski, 1931/2006a). 
Nos casos de afasia amnésica, em que ocorre dissociação da unidade de formação de conceitos, havendo prejuízo na utilização da linguagem enquanto meio para a comunicação, a vontade também retorna ao seu estado inferior, pois não há formação simbólica da ação, de modo que é alterada a possibilidade de estruturar intenções e tomar decisões a partir da vontade. Esse fato evidencia outra característica importante para compreender a vontade como uma função psicológica superior: associá-la à formulação simbólica do pensamento e perceber que a ação volitiva surge antes mesmo da sua execução (Vygotski, 1931/2006a).

Os casos de afasia evidenciam ainda a importância de estruturas de mediação para a expressão da vontade. Goldstein (1950) retrata o caso de um paciente que não conseguia atender ao comando 'feche os olhos', mas quando se solicitava que simulasse como seus olhos ficavam quando dormia, ele, então, era capaz de fechá-los. Remetendo-se a este relato, Vygotski (1932/2003) infere que, quando o paciente simula estar dormindo, o fechar os olhos não decorre de uma ação de controle do próprio corpo, mas apenas realiza um ato reflexo. Esse exemplo ratifica a compreensão de que a vontade direcionada para um fim proposta por Vygotski não está regulada pela simples relação entre um estímulo e uma resposta, mas é, necessariamente, perpassada por estímulos auxiliares/ meios que constituem os signos e são fundamentais para o domínio dos atos volitivos.

A esquizofrenia, finalmente, é também analisada por Vygotski no que tange às alterações da vontade. Para ele, a manifestação dessa condição é acompanhada da desintegração da consciência de personalidade e, também, da atividade voluntária, de forma que a ruptura nas formas de pensamento abstrato e conceitual faz com que o indivíduo não seja capaz de orientar sua própria vontade:

En la esquizofrenia, todas las funciones superiores, todas las síntesis psicológicas superiores; incluidas la conciencia de la realidad y la autoconciencia de la personalidad, recorren el camino inverso al desarrollo y repiten en orden inverso todo el camino del desarrollo directo y la formación de esas síntesis en el período de la maduración sexual (Vygotski, 1931/2006a, p. 197).

Considerando a importância das três condições citadas para o estudo da formação e expressão dos processos volitivos, torna-se possível pontuar alguns princípios gerais referentes à conceituação teórica vygotskiana acerca da vontade. Não obstante, uma vez que a realização do ato voluntário é filosoficamente articulada com a manifestação da liberdade humana, é imprescindível destacar seu entendimento sobre essa ideia.

O autor pontua que a liberdade humana se expressa a partir da compreensão das leis naturais orientando-as para fins específicos (Vygotski, 1931/2006a). A liberdade é, portanto, a possibilidade de apreender conscientemente situações que estão postas diante do ser humano (Vygotski, 1931/1995c). Como afirma Toassa (2004), encontra-se nas obras de Vygotski

a liberdade como "livre-necessidade", "necessidade gnoseológica": uma nova necessidade que consiste na atribuição de novos sentidos às informações sensoriais, na aprendizagem do uso de instrumentos e na criação de novos meios de domínio da realidade natural, necessidade cuja origem pode ser compreendida com base nas relações sociais mediadoras da relação homem-natureza. (p. 7)

Para o autor bielo-russo, a vontade não consiste em uma disposição meramente interna ao indivíduo, como faz supor a ideia de "livre arbítrio", sendo, então, concebida como dependente de motivos externos: "la ilusión del libre albedrío se perde tan pronto como pretendemos analizar el determinismo de la voluntad, su dependencia de los motivos" (Vygotski, 1931/1995c, p. 287). Dessa forma, o ato volitivo é mediado por motivos que são externos ao momento de execução desse ato, e o domínio do próprio comportamento deverá ser analisado considerando fatores que não estarão, necessariamente, evidenciados no momento da ação, rompendo assim com o princípio estímulo-resposta.

Para compreender a vontade, segundo Vygotski, é necessário ter em mente que a eleição por determinado comportamento ou ação se dá previamente a sua realização. Para o autor, esse mecanismo é estruturado pelo dinamismo que coordena a estruturação da vontade como uma função psicológica superior, que depende essencialmente da presença de motivos auxiliares, cujo papel é determinante na vontade direcionada a um fim. Por exemplo, um indivíduo que reluta em levantar da cama, mesmo sabendo que não pode mais continuar deitado, utiliza de um recurso que atua como um motivo auxiliar para se obrigar a levantar, por exemplo, contar de um até três. Ao fornecer esse exemplo, Vygotski esclarece que o motivo criado pelo sujeito, externo à sua ação, é fundamental para seu ato volitivo, pois funciona como uma ferramenta que mediatiza a escolha de levantar-se da cama e o impele a realizar essa ação (Vygotski, 1931/1995c).

A relevância dos motivos auxiliares nesse processo também se evidencia, para Vygotski, quando se investigam situações nas quais, em tese, o indivíduo teria uma alta propensão em evitá-las, mas que a construção de um sentido ou propósito vinculado ao seu ato volitivo aumenta ou sustenta a manutenção da escolha. Por exemplo, pessoas persistem em uma greve de fome ou suportam intensa dor devido ao estabelecimento de um motivo auxiliar (por exemplo, um projeto ideológico ou uma promessa religiosa) que dá significado àquela decisão (Vygotski, 1931/1995c). 
A vontade também será considerada por Vygotski como um fenômeno paradoxal, pois gera concomitantemente atos volitivos e não-volitivos. $\mathrm{O}$ autor explica esse fenômeno destacando que há dois processos vinculados à ação voluntária: a decisão e a execução. A decisão diz respeito à criação de uma relação funcional entre o contexto em que o indivíduo atuará e a construção dos motivos auxiliares. Já a execução indica o momento de realização da decisão já tomada, a qual pode ser vista como um ato quase automático, predeterminado. Sustenta-se, assim, a hipótese de que os motivos auxiliares se apresentam como os fatores primordiais para o desenvolvimento e expressão da vontade, sendo distintos dos estímulos, pois geram um conflito permanente no processo volitivo, uma vez que preveem uma constituição histórica, orientada por um movimento de superação dialética (Vygotski, 1931/1995c).

\section{Considerações finais}

Visando articular a manifestação do craving com o conceito de vontade como uma função psicológica superior, a compreensão da vontade por Vygotski surge como uma possibilidade de diferenciação do craving (eu quero) e da compulsão (eu vou). Isso é possível, em especial, quando o autor trata do paradoxo da vontade, expresso pelo fato de que a consecução dos objetivos da ação individual envolve tanto atos volitivos (decisão) quanto não-volitivos (execução). Nesse sentido, quando alguém afirma que usa determinada droga por ter visto um amigo usando, ou por frequentar um ambiente que traz a sua memória uma situação de uso, entende-se que a ação empreendida por ele naquele momento (usar certa droga) constitui um ato não-volitivo, que outrora fora estabelecido voluntariamente por meio da utilização de motivos auxiliares que estruturam a formação dos sentidos e significados sobre aquela substância psicoativa e o contexto de uso.

Com efeito, quando o modelo neurobiológico discorre acerca dos "gatilhos" que levam ao uso de uma substância, ou quando o modelo cognitivo fala sobre crenças de controle que impedem o uso, é preciso considerar que o ato de ceder ao uso ou de evitá-lo não é estabelecido no momento em que se tem contato com o estímulo (droga), mas previamente. Nesse sentido, a vontade será apreendida em Vygotski como uma dimensão concreta da ação, levando à compreensão de que a experiência histórica e social mediatiza essencialmente a decisão sobre o uso de drogas. A perpetuação do discurso de que o uso prejudicial de determinada substância psicoativa decorre, em última instância, de uma escolha do sujeito, omite a correlação desse uso com o contexto de vida com os quais ele se defrontou e se defronta.

Essas considerações também permitem problematizar a eficácia das práticas de internação às quais se recorre para o tratamento de pessoas que fazem uso prejudicial de álcool e outras drogas. Uma vez que se observa que a execução da ação (compulsão) não é estabelecida no momento em que há contato com a droga, e sim anteriormente, como um processo de decisão (craving) que se estrutura a partir de circunstâncias concretas da vida em sociedade, é controverso defender que o afastamento da droga promoveria a desintegração de um conjunto de relações que fomentam a persistência no uso.

As pesquisas sobre o craving ora revisadas evidenciaram uma correlação positiva entre a qualidade de vida e a resistência à fissura, de modo que se torna importante conjecturar sobre as condições viabilizadas por instituições com características asilares no tratamento de usuários de álcool e outras drogas. É importante ressaltar que a atenção à qualidade de vida dos indivíduos requer que se promova o acesso a bens e serviços essenciais e condições de vida dignas, pois assim será possível constituir novos conjuntos de representações simbólicas, ou seja, novos motivos auxiliares, que direcionarão a vontade para fins que sejam menos danosos com relação àqueles advindos do uso problemático de drogas.

No que tange à investigação sobre a hipótese do craving como alteração da vontade enquanto uma função psicológica superior, foi importante considerar os estudos desenvolvidos por Vygotski a respeito da histeria, da afasia e da esquizofrenia, nos quais o autor demonstrou que nessas condições ocorreria uma regressão a estados inferiores das funções psicológicas. Um ponto crítico destacado por Vygotski para o entendimento conceitual dessa regressão consistiu em observar alterações dos processos da consciência e do pensamento.

Considerando que as manifestações do craving envolvem a constituição de sentidos acerca dos benefícios oferecidos pela droga (prazer), ou pela retirada de sensações que são negativas (desprazer), durante o uso, pode-se perceber que há uma lógica estruturante criada pelo próprio usuário na relação estabelecida com a droga. Tais sentidos correspondem ao princípio da mediação dos signos no desenvolvimento das funções psicológicas superiores proposto por Vygotski, no qual admite-se que é precisamente pela introdução de estímulos artificiais, ou seja, aqueles que o próprio indivíduo confere significado, que o homem atua como o que "forma desde fuera conexiones en el cerebro, lo dirige y a través de él, gobierna su propio cuerpo" (Vygotski, 1931/1995b, p. 85).

Assim, quando o craving leva a um ato de consumo, pode-se observar que se trata da manifestação de um ato não-volitivo que constitui um segundo momento da vontade direcionada para um fim (função psicológica superior). Todavia, não há nesse contexto uma regressão a um estado psicológico rudimentar, mas sim a expressão de uma ação que é decorrente da estruturação do pensamento e da consciência por meio dos motivos auxiliares. Vale salientar que apreender o craving como uma ação governada pelos processos psicológicos superiores decorre de uma análise histórica do fenômeno da vontade que demonstra a presença de múltiplos determinantes e condicionantes no complexo 
de relações que mediatizam a atividade humana. Sendo assim, a defesa da proposição de que não há uma regressão das funções psicológicas na manifestação do craving ultrapassa concepções dualistas, como as usadas nos modelos comportamentais, neurobiológicos e cognitivos, nos quais a relação estímulo-resposta é, em última instância, o "gatilho" para o uso das substâncias psicoativas.

Além disso, considerando que a vontade permanece sendo expressa como uma função psicológica superior na manifestação do craving, observa-se que linhas de mínima resistência podem se tornar de máxima a fim de que se consiga ter acesso à droga. Esse fato é observado, por exemplo, quando Chaves et al. (2011) afirmam que

O esforço despendido para a obtenção de crack não é proporcional ao seu retorno. L28FU8m [sujeito da pesquisa] relatou ter desmontado seu guarda-roupa e ter andado com ele nas costas até a boca (local onde se vende drogas) em troca de duas pedras de crack (p. 1172, grifos do autor).

Dessa forma, a manifestação do craving se trata de um fenômeno social, cultural, histórico e singular. Nesse sentido, as estratégias de manejo que podem ser depreendidas da discussão do conceito de vontade em Vygotski envolvem não apenas um engajamento do indivíduo quanto ao seu desejo de interromper o uso, mas inclui também toda a lógica social, política e histórica que preside a construção dos significados sobre o uso de drogas. Nesse sentido, levando-se em conta as proposições do autor bielo-russo, programas de tratamento que pretendam lidar apropriadamente com o craving não podem restringir-se meramente ao manejo mais imediato de suas manifestações, mas devem incorporar oportunidades que possibilitem ao indivíduo elaborar os motivos e as decisões envolvidas na origem e no desenvolvimento de um padrão problemático de uso de álcool e outras drogas.

\title{
The will in Vygotsky: contributions to the understanding of the "craving" in drug addiction
}

\begin{abstract}
Craving is a central issue in the care of people with problems due to the use of alcohol and other drugs, and is considered an inability to control the desire for consumption. However, there is no clear definition of this phenomenon. We investigated the concept of will in the works of Lev S. Vygotsky (1896-1934), considering that his approach could contribute to understanding the craving. We reviewed the literature on craving and performed a focal analysis of the concept of will in selected texts by Vygotsky. Despite the controversies over the definition of the craving phenomenon, Vygotsky's proposition that the will is a superior psychological function mediated by auxiliary motives makes it possible to deepen the understanding of the craving. Craving management thus depends not only on individual initiative, but also on questions about the social, political, and historical logic that presides over the meanings of drug use.
\end{abstract}

Keywords: craving, Vygotsky, will, drugs.

\section{Le volonté chez Vygotski : contributions à la compréhension d'avidité dans la dépendance des drogues}

Resumé : L'avidité (craving) est un point central pour le soin des personnes ayant problèmes issus de l'utilisation de l'alcool et d'autres drogues envisagée comme l'incapacité de contrôler le désir de consommation. Cependant, il n'y a pas de définition univoque sur ce phénomène. On a recherché le concept de volonté chez Lev S. Vygotski (1896-1934) en envisageant que son approche pourrait contribuer à la compréhension de l'avidité. On a effectué une révision de littérature autour du craving et une analyse focale du concept de volonté dans des textes sélectionnés de Vygotski. Malgré les controverses sur la définition du phénomène d'avidité, la proposition de Vygotski autour de la volonté comme fonction psychologique supérieure médiate par motifs auxiliaires permet d'enrichir la compréhension du craving. Le maniement de l'avidité ne dépend pas seulement d'une initiative individuelle, mais aussi des interrogations sur la logique sociale, politique et historique qui oriente les sens de I'utilisation des drogues.

Mots-clés: craving (avidité), Vygotski, volonté, drogues.

\section{La voluntad en Vygotski: contribuciones a la comprensión del craving en la drogadicción}

Resúmen: La fisura (craving) es un tema central en la atención de personas con problemas derivados del uso de drogas, considerada una incapacidad para controlar el deseo de consumo. Sin embargo, no existe una definición única de este fenómeno. Se investigó el concepto de voluntad de Lev S. Vygotsky (1896-1934) teniendo en cuenta que podría contribuir a la comprensión de la fisura. Se realizó una revisión bibliográfica sobre el deseo, y un análisis focal del concepto de voluntad en textos seleccionados de Vygotski. A pesar de las controversias en la definición del fenómeno de la fisura, la proposición de Vygotsky sobre la voluntad como función psicológica superior mediada por motivos auxiliares hace posible ampliar la 
comprensión del craving. El tratamiento de la fisura no sólo depende de una iniciativa individual, sino también de preguntarnos acerca de la lógica social, política e histórica que preside los significados del consumo de drogas.

Palabras clave: craving (fisura), Vygotski, voluntad, drogas.

\section{Referências}

Araujo, R. B., Castro, M. D. G. T. D., Pedroso, R. S., Santos, P. L. D., Leite, L., Rocha, M. R. D., \& Marques, A. C. P. R. (2011). Validação psicométrica do Cocaine Craving Questionnaire-Brief - Versão Brasileira Adaptada para o Crack para dependentes hospitalizados. Jornal Brasileiro de Psiquiatria, 60(4), 233-239.

Araujo, R. B., Oliveira, M. D. S., Moraes, J. F. D. D., Pedroso, R. S., Port, F., \& Castro, M. D. G. T. D. (2007). Validação da versão brasileira do Questionnaire of Smoking Urges-Brief. Revista de Psiquiatria Clínica, 34(4), 166-175.

Araujo, R. B., Oliveira, M. D. S., Nunes, M. L. T., Piccoloto, L. B., \& Melo, W. V. (2004a). A avaliação do craving em alcoolistas na síndrome de abstinência. Psico-USF, 9(1), 71-76.

Araujo, R. B., Oliveira, M. D. S., Pedroso, R. S., Miguel, A. C., \& Castro, M. D. G. T. D. (2008). Craving e dependência química: conceito, avaliação e tratamento. Jornal Brasileiro de Psiquiatria, 57(1), 57-63.

Araujo, R. B., Oliveira, M., Piccoloto, L. B., \& Szupszynski, K. P. D. R. (2004b). Sonhos e craving em alcoolistas na fase de desintoxicação. Revista de Psiquiatria Clínica, 31(2), 63-69.

Araujo, R. B., Pedroso, R. S., \& Castro, M. D. G. T. D. (2010). Adaptação transcultural para o idioma português do Cocaine Craving Questionnaire-Brief. Revista de Psiquiatria Clínica, 37(5), 195-198.

Balbinot, A. D., Alves, G. S. L., Amaral Junior, A. F. D., \& Araujo, R. B. (2011). Associação entre fissura e perfil antropométrico em dependentes de crack. Jornal Brasileiro de Psiquiatria, 60(3), 205-219.

Balbinot, A. D., Araujo, R. B., \& Santos, P. L. D. (2014). Variação na frequência cardíaca e intensidade do craving durante a exposição a estímulo em dependentes de crack. Revista Brasileira de Terapia Comportamental e Cognitiva, 16(3), 23-33.

Chaves, T. V., Sanchez, Z. M., Ribeiro, L. A., \& Nappo, S. A. (2011). Fissura por crack: comportamentos e estratégias de controle de usuários e ex-usuários. Revista de Saúde Pública, 45(6), 1168-75.

Comissão Global de Políticas sobre Drogas. (2011). Guerra às drogas. Relatório final da Comissão Global de Politicas sobre Drogas. Recuperado em 3 de novembro de 2016, de https://bit.ly/2DWbbS9

Corrêa Filho, J. M., \& Baltieri, D. A. (2012). Psychosocial and clinical predictors of retention in outpatient alcoholism treatment. Revista Brasileira de Psiquiatria, 34(4), 413-421.
Glassmann, A. H., Jackson, W. K., Walsh, B. T., Roos E, S. P., \& Rosenfeld, B. (1984). Cigarette craving, smoking withdrawal, and clonidine. Science, 226, 864-866.

Goldstein, K. (1950). Transtornos del lenguaje. Barcelona: Editorial Cientifico Medica.

Fiore, M. (2012). O lugar do Estado na questão das drogas: o paradigma proibicionista e as alternativas. Novos Estudos: Cebrap, 92, 9-21.

Fonseca-Janes, C. X., \& Lima, E. A. (2013). O processo de formação de conceitos na perspectiva vigotskiana. Educação e Contemporaneidade, 22(39), 229-237.

Karam, M. L. (2008). A Lei 11.343/06 e os repetidos danos do proibicionismo. In B. C. Labate, S. L. Goulart, M. Fiore, E. MacRae, \& H. Carneiro (Orgs.), Drogas e cultura: novas perspectivas (pp.105-120). Salvador: EdUFBA

Kozlowski, L. T., \& Wilkinson, D. A. (1987). Use and misuse of the concept of craving by alcohol, tobacco, and drug researchers. British Journal of Addiction, 82, 31-36.

Lima, T. C., \& Mioto, R. C. T. (2007). Procedimentos metodológicos na construção do conhecimento científico: a pesquisa bibliográfica. Revista Katálysis, 10(1), 37-45.

Leontiev, A. (1978). O desenvolvimento do psiquismo. Lisboa: Horizonte.

Luria, A. R. (1991). A atividade consciente do homem e suas raízes histórico-sociais. In A. R. Luria, Curso de Psicologia Geral (Vol. 1, 2a ed., pp. 71-84). Rio de Janeiro, RJ: Civilização Brasileira.

Marlatt, G. A. (1987). Craving notes. British Journal of Addiction, 82(1), 42-44.

Passos, E. H., \& Souza, T. P. (2011). Redução de danos e saúde pública: construções alternativas à política global de "guerra às drogas". Psicologia \& Sociedade, 23(1), 154-162.

Pedroso, R. S., Castro, M. D. G. T. D., \& Araujo, R. B. (2009). Marijuana Craving Questionnaire (MCQ-SF/ Versão Brasil): validação semântica. Jornal Brasileiro de Psiquiatria, 58(4), 218-222.

Prestes, Z. (2012). O rigor metodológico em pesquisa bibliográfica. Ensino em Re-Vista, 19(2), 403-407.

Rodrigues, T.(2012). Narcotráfico e militarização nas Américas: vício de guerra. Contexto Internacional, 34(1), 9-41.

Santos, L. G., \& Leão, I. B. (2014). O inconsciente sóciohistórico: aproximações de um conceito. Psicologia \& Sociedade, 26(spe2), 38-47.

Santos, M. P. D., Rocha, M. R. D., \& Araújo, R. B. (2014). O uso da técnica cognitiva substituição por imagem positiva no manejo do craving em dependentes de crack. Jornal Brasileiro de Psiquiatria, 63(2), 121-126. 
Santos, V. E., Soares, C. B., \& Campos, C. M. S. (2010). Redução de danos: análise das concepções que orientam as práticas no Brasil. Physis: Revista de Saúde Coletiva, 20(3), 995-1015.

Selau, B., \& Boéssio, C. P. D. (2012). A vontade em L. S. Vigotski. In Seminário de Pesquisa em Educação da Região Sul-ANPED Sul, 9, pp. 1-15, Caxias do Sul, RS. Recuperado em 31 de agosto de 2015, de https://bit. ly/2pzJcU1

Tiburi, M., \& Dias, A. C. (2013). Sociedade fissurada: para pensar as drogas e a banalidade do vício. Rio de Janeiro, RJ: Civilização Brasileira.

Toassa, G. (2004). Conceito de liberdade em Vigotski. Psicologia: Ciência e Profissão, 24(3), 2-11.

Toassa, G. (2006). Conceito de consciência em Vigotski. Psicologia USP, 17(2), 59-83.

Vela, D. C., Abadías, M. E., Vidal, E. F., Munuera, E. I., \& Carvacho, M. S. (2004). El craving, un componente essencial em la abstinencia. Revista de la Asociación Española de Neuropsiquiatría, 89, 93-112.

Vygotski, L. S. (1995a). Método de investigación. In L. S. Vygotski, Obras escogidas: problemas del desarrollo de la psique (Vol. 3, pp. 47-96). Madrid: Visor. (Trabalho original publicado em 1931)

Vygotski, L. S. (1995b). Estructura de las funciones psíquicas superiores. In L. S. Vygotski, Obras escogidas: Problemas del desarrollo de la psique (Vol. 3, pp. 121-138). Madrid: Visor. (Trabalho original publicado em 1931)

Vygotski, L. S. (1995c). Dominio de la propia conducta. In L. S. Vygotski, Obras escogidas: problemas del desarrollo de la psique (Vol. 3, pp. 285-302). Madrid: Visor. (Trabalho original publicado em 1931)

Vygotski, L. S. (1999). A consciência como problema da psicologia do comportamento. In L. S. Vigotski, Teoria e método em psicologia (pp. 55-85). São Paulo, SP: Martins Fontes. (Trabalho original publicado em 1925)

Vygotski, L. S. (2001a). Estudo experimental do desenvolvimento dos conceitos. In L. S. Vigotski, $A$ construção do pensamento e da linguagem (pp. 151239). São Paulo, SP: Martins Fontes. (Trabalho original publicado em 1932).

Vygotski, L. S. (2001b). Pensamento e palavra. In L. S. Vigotski, A construção do pensamento e da linguagem (pp. 395-486). São Paulo, SP: Martins Fontes. (Trabalho original publicado em 1932)

Vygotski, L. S. (2003). O problema da vontade e seu desenvolvimento na infância. In L. S. Vigotski, $O$ desenvolvimento psicológico na infância (pp. 131146). São Paulo, SP: Martins Fontes. (Trabalho original publicado em 1932)

Vygotski, L. S. (2006a). Desarrollo de las funciones psíquicas superiores em la edad de transición. In L. S. Vigotski, Obras escogidas: psicología infantil (Vol. 4, 2a ed., pp. 117-203). Boadilla del Monte, Espanha: A. Machado Libros. Trabalho original publicado em 1931).

Vygotski, L. S. (2006b). El desarrollo del pensamiento del adolescente y la formación de conceptos. In L. S. Vigotski, Obras escogidas: psicología infantil (Vol. 4, 2a ed., pp. 47-116). Boadilla del Monte, Espanha: A. Machado Libros. (Trabalho original publicado em 1931).

Zeni, T. C., \& Araujo, R. B. (2011). Relação entre o craving por tabaco e o craving por crack em pacientes internados para desintoxicação. Jornal Brasileiro de Psiquiatria, 60(1), 28-33. 